\title{
Viscosity Study of Polymer Solutions through Shiio Model
}

\author{
A. Inigomary Rita ${ }^{1}$, K. Maria Eugenie Pia ${ }^{2}$ \\ PG and Research Department of Physics, Holy Cross College, Trichy, Tamilnadu, India
}

\begin{abstract}
Density, velocity and viscosity measurements were made for the solutions of Poly Vinylidene Fluoride in polar solvent for different concentrations at different temperatures. According to Shiio, the compressibility of the bound solvent cannot be neglected in the case of polymers, as it is having some appreciable value. Following this model, viscosity of the solvated part ( $\left.\eta_{s}\right)$ is computed and the variation of $\eta_{s}$ with molar concentration $\left(n_{2}\right)$ is studied. The methodology of arriving at the molar solvated volume $\left(\Phi_{s}\right)$ from $\left(\eta_{s}\right)$ is verified by comparing the values of $\Phi_{s}$ with the value computed using the traditional equation. The correlation between Huggins's coefficient and the constants describing the solvated part is analyzed.
\end{abstract}

Keywords: ultrasonic study, solvation number, Molar solvated volume, polyvinylidene fluoride, Shiio model

\section{Introduction}

During solvation in aqueous electrolytic solutions, the solvent molecules are compressed by the strong electric field of the solute ion, thus forming a hard core. Assuming that the compressibility of the bound water and that of the ion is negligible, Passynskii ${ }^{1}$ and other investigators have evaluated the hydration number from the measurement of compressibility. But, according to Shiio et al., ${ }^{2}$ the compressibility of the bound solvent cannot be neglected in the case of polymers as it has some appreciable value. Considering the compressibility of the solution to be due to the free solvent part and that due to the solvated part, they have derived a most general formula. On this basis expression for the viscosity of the solvated part $\left(\eta_{\mathrm{s}}\right)$ has been computed by Kalyanasundaram et $\mathrm{al}^{3}$. In the present paper, the methodology of arriving at $\eta_{\mathrm{s}}$ and the molar solvated volume $\Phi_{s}$ from $\eta_{s}$ is verified for the solutions of polyvinylidene fluoride in polar solvent. The intrinsic viscosity is computed from the viscosity of the solvated part and the correlation between Huggins's coefficient and the constants describing the solvated part is analyzed.

\section{Experimental}

The solutions of polyvinylidene fluoride of concentration range from $0 \% \mathrm{w}$ to $2 \% \mathrm{w}$ were prepared by dissolving known quantities of PVDF (Sigma Aldrich Chemical Pvt.Ltd., Bangalore) in polar solvent namely Dimethyl sulphoxide. Ultrasonic velocities of the solutions were measured using a fixed frequency continuous wave ultrasonic interferometer (Model F80, Mittal Enterprises, New Delhi) to an accuracy of \pm 0.1 at a frequency of $2 \mathrm{MHz}$ at $308 \mathrm{~K}, 313 \mathrm{~K}, 318 \mathrm{~K}$ and $323 \mathrm{~K}$. The temperature of the samples was maintained constant to an accuracy of $\pm 0.1^{\circ}$ using a thermostatically controlled water bath. Density was measured using $10 \mathrm{ml}$ specific gravity bottle at all above temperatures. The viscosity was measured using Ostwald's viscometer to an accuracy of $\pm 0.2 \%$.

\section{Theory}

Viscosity of solvated part and molar solvated volume

The viscosity of the solution is assumed to be the sum of viscosity of the free solvent part and the viscosity of the solvated part. Then,

$$
\eta=\left(n_{1}-n_{2} S\right) \frac{\eta_{0}}{N}+n_{2} \eta_{s}
$$

where $\eta_{0}$ is the viscosity of the pure solvent and $\eta_{s}$ is the viscosity of the solvated part given by

$$
\eta_{\mathrm{s}}=\frac{1}{\mathrm{n}_{2}}\left[\eta-\left(\beta-\mathrm{nS}_{2} \frac{\beta_{\mathrm{h}}}{\mathrm{N}}\right) \frac{\eta_{0}}{\beta_{0}}\right]
$$

where $\beta_{\mathrm{h}}$ denotes the compressibility of the unit mole of the solvated part.

The molar solvated volume $\Phi_{\mathrm{s}}$ is obtained from $\eta_{\mathrm{s}}$ as

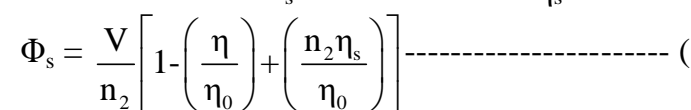

$\Phi_{\mathrm{s}}$ is usually computed using the adiabatic compressibility data (traditional method) through the relation

$$
\Phi_{\mathrm{s}}=V_{1}\left(\frac{N \Delta \beta S \beta}{\beta_{0} n_{2} \beta} \frac{h}{0}\right)
$$

\section{Intrinsic Viscosity from the Viscosity of solvated part}

Huggin's ${ }^{4}$ polynomial relation for the variation of viscosity with the concentration is

$\eta / \eta_{0}=1+A_{\eta} n_{2}+B_{\eta} n_{2}^{2}$

Rearranging the equation,

$$
\left[\left(\eta / \eta_{0}\right)-1\right] / n_{2}=A_{\eta}+B_{\eta} n_{2}
$$

Since $\Phi_{\mathrm{s}}$ varies linearly with $\mathrm{n}_{2}$ we can write,

$$
\Phi_{\mathrm{s}}=\Phi_{\mathrm{so}}+\mathrm{S}_{\mathrm{s}} \mathrm{n}_{2}
$$

where $\Phi_{\text {so }}$ is the molar solvated volume at infinite dilution and $\mathrm{S}_{\mathrm{s}}$ is the slope of the plot of $\Phi_{\mathrm{s} v \mathrm{~s}} \mathrm{n}_{2}$.

Assuming $\eta_{\mathrm{s}}$ to vary linearly with $\mathrm{n}_{2}$ like $\Phi_{\mathrm{s}}$, we have,

$$
\eta_{\mathrm{s}}=\eta_{\mathrm{so}}+\mathrm{S}_{\eta} \mathrm{n}_{2}
$$

where $\eta_{\text {so }}$ is the viscosity of the solvated part at infinite dilution and $S_{\eta}$ is the slope of the plot of $\eta_{s}$ vs $n_{2}$. From equation (3), 


\section{International Journal of Science and Research (IJSR) \\ ISSN (Online): 2319-7064}

Index Copernicus Value (2013): 6.14 | Impact Factor (2015): 6.391

$$
\frac{1}{\mathrm{n}_{2}}\left(\frac{\eta}{\eta_{0}}-1\right)=\left(\frac{\eta_{\mathrm{s}}}{\eta_{0}}\right)-\left(\frac{\Phi_{\mathrm{s}}}{\mathrm{V}}\right)
$$

Substituting the values of $\Phi_{\mathrm{s}}$ and $\eta_{\mathrm{s}}$ we get

$$
\frac{1}{\mathrm{n}_{2}}\left(\frac{\eta}{\eta_{0}}-1\right)=\left(\frac{\eta_{\mathrm{s} 0}+\mathrm{S}_{\eta_{1}} \mathrm{n}_{2}}{\eta_{0}}\right)-\left(\frac{\Phi_{\mathrm{s} 0}+\mathrm{S}_{\mathrm{s}} \mathrm{n}_{2}}{\mathrm{~V}}\right)
$$

Comparing the coefficients of equations (5) and (9),

$$
\begin{array}{r}
\mathrm{A}_{\eta}=\left(\frac{\eta_{\mathrm{s} 0}}{\eta_{0}}\right)-\left(\frac{\Phi_{\mathrm{s} 0}}{\mathrm{~V}}\right) \\
\mathrm{B}_{\eta}=\left(\frac{\mathrm{S}_{\eta}}{\eta_{\mathrm{0}}}\right)-\left(\frac{\mathrm{S}_{\mathrm{s}}}{\mathrm{V}}\right)
\end{array}
$$

The coefficient of $A_{\eta}$ is the measure of intrinsic viscosity at infinite dilution[ $\eta]$ and it can be computed from the knowledge of $\varphi_{\text {so }}$ and $\eta_{\text {so }}$

\section{Results and Discussion}

The values of the viscosity of the solvated part $\eta_{\mathrm{s}}$ and molar solvated volume $\varphi_{\mathrm{s}}$ from $\eta_{\mathrm{s}}{ }^{5}$ have been computed for different concentrations at different temperatures and presented in table (1). In order to verify the methodology, $\varphi_{\mathrm{s}}$ have also been computed using the traditional equation (4). There is a good agreement between the two values of $\varphi_{\mathrm{s} \text {. The }}$ viscosity of the solvated part is found to vary linearly with concentration like molar solvated volume (Fig1\&2) The plot $\left[\left(\eta / \eta_{0}\right)-1\right] / n_{2} v_{s} n_{2}$ (Fig 3 ) gives the Huggin's coefficients $A_{\eta}$ and $B_{\eta}$. They are also calculated using $\varphi_{\text {so }}$ and $\eta_{\text {so }}$ and presented in table (2). The close agreement between the values computed theoretically and computed through Huggin's relation verifies the methodology adopted, thereby showing that the polynomial relation suggested by Huggin's

\begin{tabular}{|c|c|c|c|c|c|c|}
\hline TEMP & $\mathrm{n}_{2} \mathrm{M}$ & $\eta \times 10^{3} \mathrm{Nsm}^{-2}$ & $\eta_{\text {red }} M^{-1}$ & $\eta_{\mathrm{s}} \times 10^{3} \mathrm{Nsm}^{-2} \mathrm{M}^{-1}$ & $\Phi$ Фs x 10 & $\mathbf{m}^{3} \mathbf{M}^{-1}$ \\
\hline & & & & Eqn 2 & Eqn 3 (from $\eta s)$ & Eqn 4 \\
\hline \multirow{7}{*}{$308 \mathrm{~K}$} & 0.000 & 1.47 & - & - & - & \\
\hline & 0.039 & 1.74 & 4.65 & 8.00 & 781.44 & 781.44 \\
\hline & 0.078 & 2.11 & 5.54 & 8.99 & 560.57 & 560.57 \\
\hline & 0.117 & 2.55 & 6.27 & 9.96 & 483.16 & 483.16 \\
\hline & 0.155 & 2.92 & 6.30 & 9.87 & 400.29 & 400.29 \\
\hline & 0.194 & 3.69 & 7.76 & 11.82 & 261.63 & 261.63 \\
\hline & 0.232 & 4.14 & 7.79 & 11.81 & 220.63 & 220.63 \\
\hline \multirow{7}{*}{$313 \mathrm{~K}$} & 0.000 & 1.31 & - & - & - & \\
\hline & 0.039 & 1.56 & 4.97 & 7.32 & 620.01 & 620.01 \\
\hline & 0.078 & 1.86 & 5.39 & 7.70 & 491.16 & 491.16 \\
\hline & 0.117 & 2.27 & 6.31 & 8.80 & 412.71 & 412.71 \\
\hline & 0.155 & 2.62 & 6.42 & 8.84 & 321.53 & 321.53 \\
\hline & 0.194 & 3.26 & 7.68 & 10.34 & 221.33 & 221.33 \\
\hline & 0.232 & 3.66 & 7.73 & 10.37 & 190.99 & 190.99 \\
\hline \multirow{7}{*}{$318 \mathrm{~K}$} & 0.000 & 1.19 & - & - & - & \\
\hline & 0.039 & 1.42 & 5.01 & 6.57 & 512.42 & 512.42 \\
\hline & 0.078 & 1.69 & 5.42 & 6.95 & 426.59 & 426.59 \\
\hline & 0.117 & 2.00 & 5.87 & 7.43 & 377.66 & 377.66 \\
\hline & 0.155 & 2.28 & 5.93 & 7.45 & 335.12 & 335.12 \\
\hline & 0.194 & 2.93 & 7.54 & 9.24 & 228.88 & 228.88 \\
\hline & 0.232 & 3.33 & 7.76 & 9.46 & 195.00 & 195.00 \\
\hline
\end{tabular}
can be explained in terms of $\varphi_{\text {so }}$ and $\eta_{\text {so }}$ using solvation study.

Table 1: Values of $n_{2}, \eta, \eta_{s}$ and $\Phi_{s}$ for PVDF + DMSO solution

Table 2: The values of $\eta_{s o}, S_{\eta}, A_{\eta}$ and $B_{\eta}$

\begin{tabular}{|c|c|c|c|c|c|c|}
\hline & $\mathbf{\eta}_{\mathbf{s o}} \mathbf{x 1 0}^{\mathbf{3}}$ & $\mathbf{S}_{\mathbf{\eta}} \mathbf{x} \mathbf{1 0}^{\mathbf{3}}$ & \multicolumn{2}{|c|}{$\mathbf{A}_{\boldsymbol{\eta}}$ or $[\boldsymbol{\eta}]$} & \multicolumn{2}{|c|}{$\mathbf{B}_{\boldsymbol{\eta}}$} \\
\hline 303 & 7.32 & 20.27 & 4.14 & 4.14 & 16.55 & 16.55 \\
\hline 313 & 6.57 & 17.15 & 4.33 & 4.33 & 15.34 & 15.34 \\
\hline 318 & 5.71 & 15.78 & 4.23 & 4.23 & 14.91 & 14.91 \\
\hline 323 & 5.64 & 11.75 & 4.78 & 4.81 & 12.44 & 12.44 \\
\hline
\end{tabular}

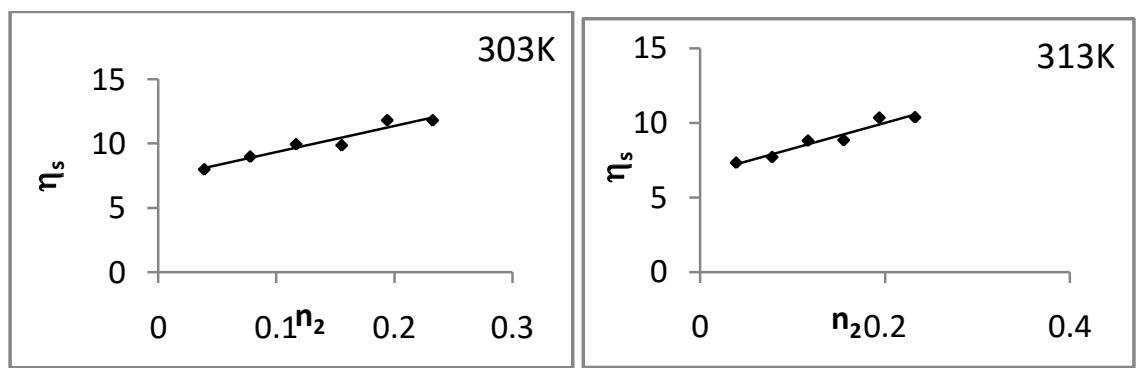


International Journal of Science and Research (IJSR)

ISSN (Online): 2319-7064

Index Copernicus Value (2013): 6.14 | Impact Factor (2015): 6.391

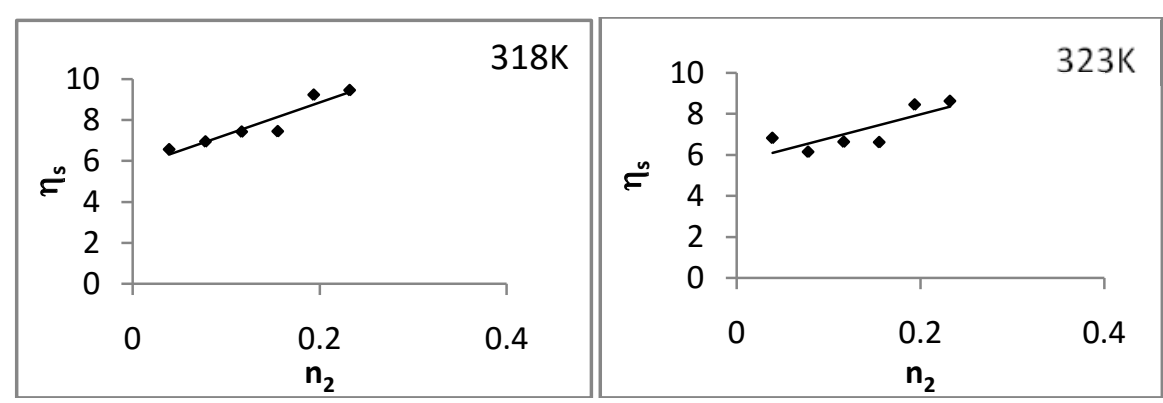

Figure 1: Variation of $\eta \mathrm{s}$ with concentration
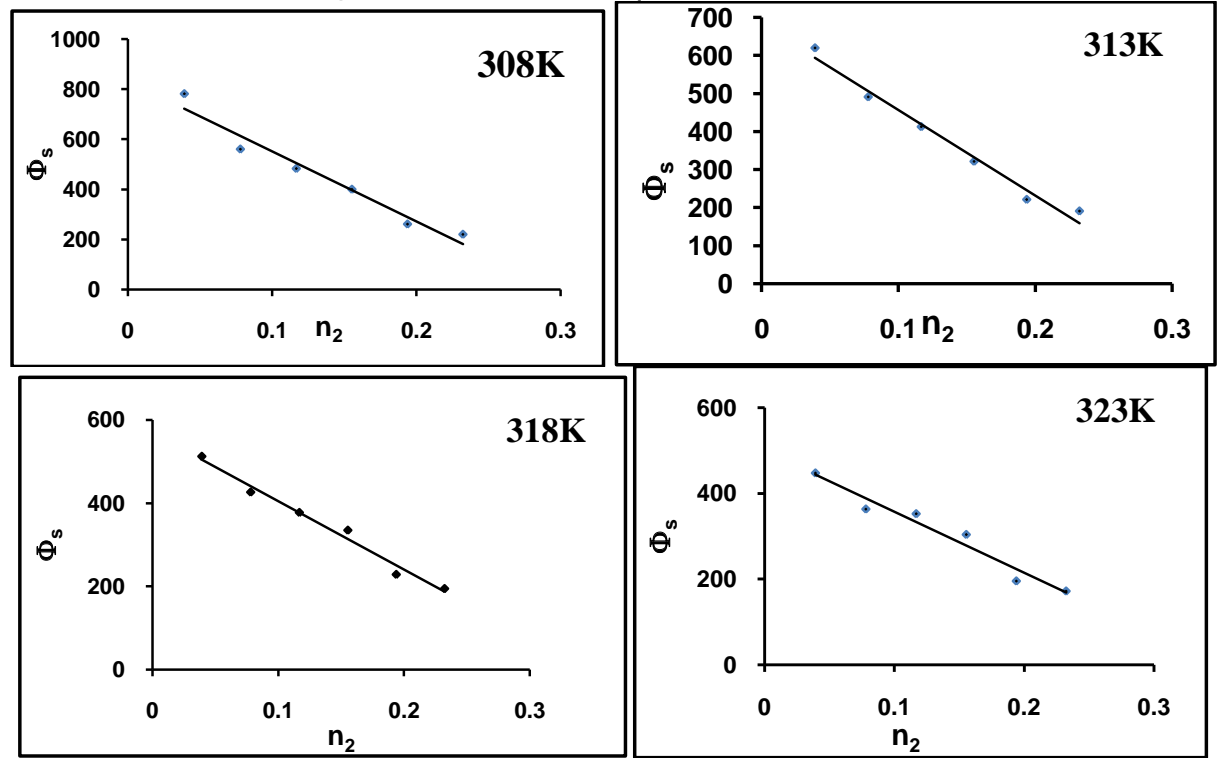

Figure 2: Variation of $\Phi$ s with concentration
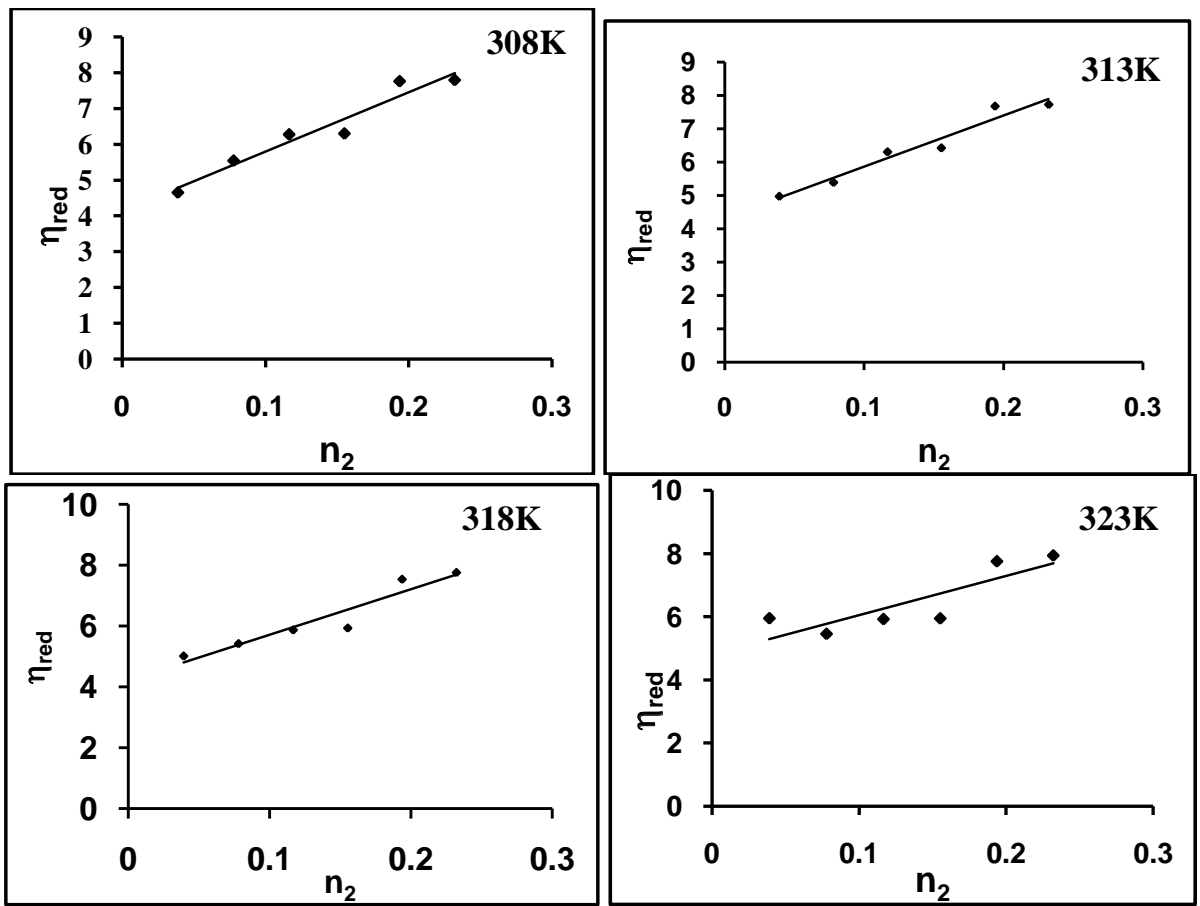

Figure 3: Variation of $\eta_{\text {red }}$ with $n_{2}$

\section{References}

[1] A.G. Passynskii, J. Polym. Sci., 29 (1958) 61.

[2] H. Shiio, J. Am. Chem. Soc., 80 (1958) 70.

[3] S. Kalyanasundaram and J. Hemalatha, J. Acous. Soc. Ind., XXVII(1-4) (1999) 383.

[4] M.L. Huggins, J. Am. Chem. Soc., 64 (1942) 2716.
[5] S. Kalyanasundaram, B. Sundaresan and J. Hemalatha, J. Polym. Mater., 17 (2000) 91.

[6] S. Kalyanasundaram and J. Hemalatha, Bull. Elec. Chem., 15 (1999) 492.

[7] S. Kalyanasundaram and B. Sundaresan, J. Polym. Mater., 16 (1999) 35-45. 